\title{
Electronic Structure and Physical-Chemistry Property Relationship for Oxazole Derivatives by Ab Initio and DFT Methods
}

\author{
Salah Belaidi and Malika Mellaoui \\ Group of Computational and Pharmaceutical Chemistry, LMCE Laboratory, Department of Chemistry, Faculty of Sciences, \\ University of Biskra, Biskra 07000, Algeria \\ Correspondence should be addressed to Salah Belaidi, salah_belaidi@hotmail.com
}

Received 30 April 2011; Revised 18 June 2011; Accepted 20 June 2011

Academic Editor: Daniel Little

Copyright ( $) 2011$ S. Belaidi and M. Mellaoui. This is an open access article distributed under the Creative Commons Attribution License, which permits unrestricted use, distribution, and reproduction in any medium, provided the original work is properly cited.

The geometric, electronic structure, effect of the substitution, and structure physical-chemistry relationship for oxazoles derivatives have been studied by ab initio and DFT theory. In the present work, the calculated values, namely, net charges, bond lengths, dipole moments, electron affinities, heats of formation, and QSAR properties are reported and discussed in terms of the reactivity of oxazole derivatives.

\section{Introduction}

The emerging resistance to antimicrobial drugs demands the synthesis of new remedies for microbial infections, which are effective against organisms resistant to currently available drugs [1].

Oxazoles and isoxazoles have an important role in the synthesis of potential medicines including antitumor, antimicrobial, anti-infective, cardiovascular, and nervous system agents [2].

There are various experimental methods developed for the synthesis of oxazole and isoxazole derivatives $[3,4]$. But there are few relatively theoretical works on oxazoles and isoxazoles [5-7].

Quantum chemistry methods play an important role in obtaining molecular geometries and predicting various properties. To obtain highly accurate geometries and physical properties for molecules that are built from electronegative elements, expensive ab initio/HF electron correlation methods are required [8]. Density functional theory methods offer an alternative use of inexpensive computational methods which could handle relatively large molecules [9].

Quantitative structure-activity relationships (QSAR) are attempts to correlate molecular structure, or properties derived from molecular structure, with a particular kind of chemical or biochemical activity. The kind of activity is a function of the interest of the user: QSAR is widely used in pharmaceutical, environmental, and agricultural chemistry in the search for particular properties. The molecular properties used in the correlations relate as directly as possible to the key physical or chemical processes taking place in the target activity [10].

In present case, we have studied the structure of oxazole Figure 1 and some of oxazole derivatives, by using ab initio method. For a complete and comparative study, we have also used DFT method.

\section{Computational Methods}

All calculations were performed by using HyperChem 8.03 software [11]. The geometries of oxazole and its methyl, cyanide derivatives and the series of oxazole derivatives were first fully optimized by molecular mechanics, with $\mathrm{MM}+$ force field $(\mathrm{rms}=0.001 \mathrm{Kcal} / \AA)$.

We also used the molecular dynamics for the conformational research, with the following options: $1000 \mathrm{~K}$, in vacuo, steep size: $0.001 \mathrm{ps}$, relaxation time: $0.1 \mathrm{ps}$. Further, geometries were fully reoptimized by using ab initio/HF (6$\left.31 G^{* *}\right)[12]$. 


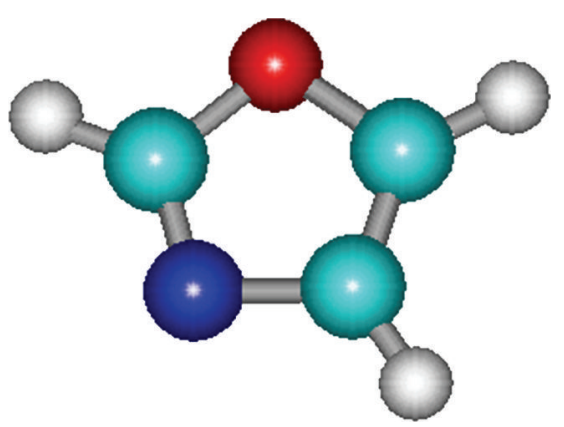

FIgURE 1: 3D conformation of oxazole (HyperChem 8.03).

TABle 1: Calculated bond lengths (angstrom) of oxazole.

\begin{tabular}{lcc}
\hline Bond length & $\begin{array}{c}\mathrm{AB} \text { initio/HF } \\
\left(6-31 \mathrm{G}^{* *}\right)\end{array}$ & $\begin{array}{c}\mathrm{DFT} / \mathrm{B} 3 \mathrm{LYP} \\
\left(6-31 \mathrm{G}^{* *}\right)\end{array}$ \\
\hline $\mathrm{O}-\mathrm{C} 2$ & 1.329 & 1.391 \\
$\mathrm{C} 2-\mathrm{N}$ & 1.268 & 1.301 \\
$\mathrm{~N}-\mathrm{C} 4$ & 1.388 & 1.417 \\
$\mathrm{C} 4-\mathrm{C} 5$ & 1.33 & 1.353 \\
$\mathrm{C} 5-\mathrm{O}$ & 1.355 & 1.404 \\
\hline
\end{tabular}

A parallel study has been made by DFT/B3LYP exchangecorrelation potential with $6-31 \mathrm{G}^{* *}$ basis [13].

The calculation of QSAR properties is performed by the module (QSAR Properties, version 8.0). QSAR Properties is a module that, together with HyperChem, allows several properties commonly used in QSAR studies to be calculated. The calculations are empirical and so, generally, are fast. The calculated results have been reported in the present work.

\section{Results and Discussion}

3.1. Geometric and Electronic Structure of Oxazole and Oxazole Systems. The efficiency of DFT/B3LYP method may be scrutinized by comparison with the results obtained by more elaborate calculation such as ab initio/HF. Present results concern bond length values for oxazole (Table 1) and charge densities (Table 2). We can note a good correlation between the ab initio and DFT for bond lengths. Charge densities calculated by the ab initio are similar than DFT method. The geometry of the oxazole is almost planar. The Dihedral angles of this molecule vary between 0.001 and 8.426 degree (Table 3 ). The lower deviations of registered dihedral angles compared with normal values were imposed essentially by a cyclic chain [7].

The calculated values of methyl-substituted oxazoles and cyanide-substituted oxazoles (Figure 2) are given in Tables 4-7. In Tables 4 and 5, heat of formation, dipole moment, HOMO (highest occupied molecular orbital), LUMO (lowest unoccupied molecular orbital), and their difference $(\Delta \mathrm{E})$ are reported for oxazole and its methyl and cyanide derivatives. In Tables 6 and 7, net atomic charges are reported also.
TABLE 2: Net charge distribution for oxazole.

\begin{tabular}{lcc}
\hline Oxazole atoms & $\begin{array}{c}\mathrm{AB} \text { initio/HF } \\
\left(6-31 \mathrm{G}^{* *}\right)\end{array}$ & $\begin{array}{c}\mathrm{DFT} / \mathrm{B} 3 \mathrm{LYP} \\
\left(6-31 \mathrm{G}^{* *}\right)\end{array}$ \\
\hline $\mathrm{O}$ & -0.527 & -0.439 \\
$\mathrm{~N}$ & -0.387 & -0.317 \\
$\mathrm{C} 2$ & 0.519 & 0.429 \\
$\mathrm{C} 4$ & -0.022 & -0.017 \\
$\mathrm{C} 5$ & 0.107 & 0.124 \\
\hline
\end{tabular}

TABLe 3: Dihedral angles in degree.

\begin{tabular}{lcc}
\hline Dihedral angles & $\begin{array}{c}\mathrm{AB} \text { initio/HF } \\
\left(6-31 \mathrm{G}^{* *}\right)\end{array}$ & $\begin{array}{c}\mathrm{DFT} / \mathrm{B} 3 \mathrm{LYP} \\
\left(6-31 \mathrm{G}^{* *}\right)\end{array}$ \\
\hline O1-C2-N3-C4 & 8.426 & 7.997 \\
C2-N3-C4-C5 & 0.001 & 0.381 \\
N3-C4-C5-O1 & 0.001 & 0.126 \\
C4-C5-O1-C2 & 5.015 & 3.021 \\
C5-O1-C2-N3 & 2.483 & 4.325 \\
\hline
\end{tabular}

Series 1:

(1) $\mathrm{R}_{1}=\mathrm{R}_{2}=\mathrm{R}_{3}=\mathrm{H}$

(2) $\mathrm{R}_{1}=\mathrm{CH}_{3}, \mathrm{R}_{2}=\mathrm{R} 3=\mathrm{H}$

(3) $\mathrm{R}_{1}=\mathrm{R} 3=\mathrm{H}, \mathrm{R}_{2}=\mathrm{CH}_{3}$

(4) $\mathrm{R}_{1}=\mathrm{R}_{2}=\mathrm{H}, \mathrm{R}_{3}=\mathrm{CH}_{3}$

(5) $\mathrm{R}_{1}=\mathrm{R}_{2}=\mathrm{CH}_{3}, \mathrm{R}_{3}=\mathrm{H}$

(6) $\mathrm{R}_{1}=\mathrm{R}_{3}=\mathrm{CH}_{3}, \mathrm{R}_{2}=\mathrm{H}$

(7) $\mathrm{R}_{1}=\mathrm{H}, \mathrm{R}_{2}=\mathrm{R}_{3}=\mathrm{CH}_{3}$

(8) $\mathrm{R}_{1}=\mathrm{R}_{2}=\mathrm{R}_{3}=\mathrm{CH}_{3}$

Series 2:

(1) $\mathrm{R}_{1}=\mathrm{R}_{2}=\mathrm{R}_{3}=\mathrm{H}$

(2) $\mathrm{R}_{1}=\mathrm{CN}, \mathrm{R}_{2}=\mathrm{R}_{3}=\mathrm{H}$

(3) $\mathrm{R}_{1}=\mathrm{R}_{3}=\mathrm{H}, \mathrm{R}_{2}=\mathrm{CN}$

(4) $\mathrm{R}_{1}=\mathrm{R}_{2}=\mathrm{H}, \mathrm{R}_{3}=\mathrm{CN}$

(5) $\mathrm{R}_{1}=\mathrm{R}_{2}=\mathrm{CN}, \mathrm{R}_{3}=\mathrm{H}$

(6) $\mathrm{R}_{1}=\mathrm{R}_{2}=\mathrm{CN}, \mathrm{R}_{3}=\mathrm{H}$

(7) $\mathrm{R}_{1}=\mathrm{H}, \mathrm{R}_{2}=\mathrm{R}_{3}=\mathrm{CN}$

(8) $\mathrm{R}_{1}=\mathrm{R}_{2}=\mathrm{R}_{3}=\mathrm{CN}$

It can be seen from the heat of formation data that approximately $9 \mathrm{kcal} / \mathrm{mol}$ is increased at each addition of methyl group, in the base compound oxazole irrespective of the number of substitutions.

The ionization potential values in compounds $\mathbf{1}-\mathbf{8}$ show a decreasing trend which depicts increasing trend in the easy flow of charges in higher energy states of these compounds. Oxygen and nitrogen contribute eight and seven electron density of oxazoles, respectively. 


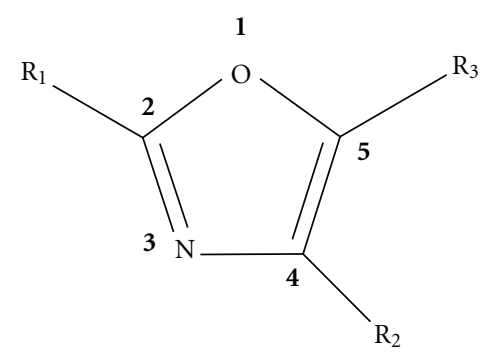

FIgURE 2: Scheme of oxazole systems.

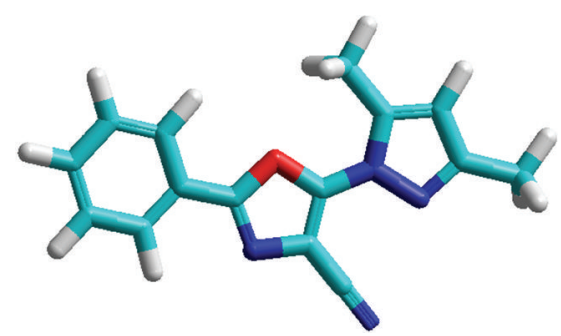

Figure 3: 3D conformation of compound 4 (HyperChem 8.03).
The negative atomic charge on oxygen is increased considerably for methyl derivatives, but on nitrogen is enhanced except for compounds 4 (Table 6). In the monosubstituted methyl group category, the 5-methyl oxazole (compound 4) shows maximum charge on 2 th position carbon $(0.390)$ which leads to nucleophilic substitution (Table 6). This is further supported by the least HOMO-LUMO energy gap (13.76) (Table 4) which depicts the chemical reactivity of the compound; the higher is the HOMO-LUMO energy gap, the lesser is the flow of electrons to the higher energy state, making the molecular hard and less reactive.

On the other hand in lesser HOMO-LUMO gap, there is easy flow of electrons to the higher energy state making it softer and more reactive (HSAB principle: hard and soft acids and bases). Hard bases have highest occupied molecular orbitals (HOMO) of low energy, and hard acids have lowest unoccupied molecular orbitals (LUMO) of high energy [14].

Compound 4 also shows maximum dipole moment value. These results are in close agreement with the experiment [15].

In the case of dimethyl-substituted, oxazole the C-2position (compound 6) shows maximum charge (0.564), least HOMO-LUMO energy gap (13.58), and high dipole moment value (Tables 4-6) which leads to preferential site of nucleophilic attack.

This conclusion finds support from experimental evidence. In search of basicity, $\mathrm{N}$ atom is predicted to be the main basic centre of the oxazole systems in accordance with the electron densities (Table 4).

The C-H hyperconjugation is the principal mode of electron release by the methyl group (pseudohetero atom) and stabilizes excited states more than ground state [16]. In the order of increasing number of conjugated methyl groups, ionization potentials (IPs) decreases in the case of compounds 1-8 as expected from those listed in Table 6.

The 2, 4, 5-trimethyl oxazole (compound $\mathbf{8}$ ) is predicted to be the most reactive with least HOMO-LUMO energy gap of all the oxazole systems and, respectively, C2, C4, and $\mathrm{C} 5$ are the most preferential sites for nucleophilic attack (Table 4).

These results are in close agreement with the experiment [15], and we found in our literature that the majority of trisubstituted oxazoles have biological activity $[3,4,10,15]$.
We note also that the methyl substituent (donor effect) has the effect of increasing the energy of the HOMO, with little change of the LUMO (Table 4).

In the present work, we have studied cyanide-substituted oxazoles along the same line of methyl-substituted oxazoles whish is for a comparative study. It is interesting to note that the heat of formation approximately $36 \mathrm{Kcal} / \mathrm{mol}$ is increased, for each addition of cyanide group irrespective of oxygen in the ring. For nitrogen atom, the negative atomic charge is considerably weakened for these cyanide derivatives (Table 7).

In monosubstituted cyanide derivatives, 2-cyano oxazole (compound 2 ) is predicted to be more chemically reactive than 5-cyano oxazole and 4-cyano oxazole on the basis of least HOMO-LUMO energy gap (Table 5).

The carbon C-2 in 2-cyano oxazole shows maximum positive charge (0.6101) leading to favored site for nucleophilic attack (Table 6). In disubstituted cyanide derivatives, 2,5-dicyano oxazole (compound 6) seems to be more reactive than the other two composites 7 and 5, due to least HOMO-LUMO energy gap (11.97) (Table 5).

The compound $\mathbf{8}$ is predicted to be the most reactive with least HOMO-LUMO energy gap of all oxazole systems. We note also that the cyanide substituent (attractor effect) lowers the energies of HOMO and LUMO. His influence on the energy of the LUMO is more important (Table 5).

\subsection{Study of Structure Physical-Chemistry Property Relation-} ship for Oxazole Derivatives. We have studied six physicalchemical properties of oxazole derivatives (ten compounds) by HyperChem software, for example, in Figure 3, the favored conformation in 3D of the compound 4. We will continue this work in the future by a quantitative calculation. QSAR properties are van der Waals-surfacebounded molecular volume, the log of the octanol-water partition coefficient $(\log P)$, polarizability, and solventaccessible surface-bounded molecular volume and molecular mass (M). Calculation of $\log P$ is carried out using atomic parameters derived by Viswanadhan and coworkers [17].

Computation of molar refractivity was made via the same method as $\log P$. Ghose and Crippen presented atomic contributions to the refractivity [18]. The solvent-accessible surface bounded molecular volume and van der Waalssurface-bounded molecular volume calculations are based 
TABLE 4: Energies of oxazole and methyl-substituted oxazoles.

\begin{tabular}{|c|c|c|c|c|c|c|}
\hline Compound & System & Heat of formation $(\mathrm{kcal} / \mathrm{mol})$ & $-\mathrm{HOMO}(\mathrm{eV})$ & LUMO $(\mathrm{eV})$ & $\Delta \mathrm{E}(\mathrm{eV})$ & $\mu(\mathrm{D})$ \\
\hline 1 & Oxazole & -1.58 & 9.534 & 4.491 & 14.024 & 1.58 \\
\hline 2 & 2-methyl oxazole & -10.57 & 9.180 & 4.629 & 13.811 & 1.38 \\
\hline 3 & 4-methyl oxazole & -11.22 & 9.222 & 4.678 & 13.900 & 1.35 \\
\hline 4 & 5-methyl oxazole & -10.40 & 9.064 & 4.691 & 13.755 & 2.16 \\
\hline 5 & 2,4-dimethyl oxazole & -20.19 & 8.908 & 4.804 & 13.709 & 1.06 \\
\hline 6 & 2,5-dimethyl oxazole & -19.32 & 8.747 & 4.801 & 13.578 & 1.88 \\
\hline 7 & 4,5-dimethyl oxazole & -19.95 & 8.780 & 4.854 & 13.634 & 1.89 \\
\hline 8 & 2,4,5-trimethyl oxazole & -28.86 & 8.497 & 4.956 & 13.454 & 1.57 \\
\hline
\end{tabular}

$\Delta \mathrm{E}$ and $\mu(\mathrm{D})$ by ab initio.

TABLE 5: Energies of oxazole and cyanide-substituted oxazoles.

\begin{tabular}{|c|c|c|c|c|c|c|}
\hline Compound & System & Heat of formation $(\mathrm{kcal} / \mathrm{mol})$ & $-\mathrm{HOMO}(\mathrm{eV})$ & LUMO (eV) & $\Delta \mathrm{E}(\mathrm{eV})$ & $\mu(\mathrm{D})$ \\
\hline 1 & Oxazole & -1.58 & 9.534 & 4.491 & 14.024 & 1.58 \\
\hline 2 & 2-cyano oxazole & 40.23 & 10.222 & 2.413 & 12.635 & 4.96 \\
\hline 3 & 4-cyano oxazole & 35.55 & 10.287 & 2.961 & 13.248 & 4.91 \\
\hline 4 & 5-cyano oxazole & 38.34 & 10.234 & 2.488 & 12.722 & 2.91 \\
\hline 5 & 2,4-dicyano oxazole & 78.73 & 10.860 & 1.660 & 13.478 & 3.94 \\
\hline 6 & 2,5-dicyano oxazole & 68.27 & 10.814 & 1.151 & 11.965 & 2.41 \\
\hline 7 & 4,5-dicyano oxazole & 77.73 & 10.837 & 1.194 & 12.031 & 5.20 \\
\hline 8 & 2,4,5-tricyano oxazole & 122.16 & 11.327 & 0.313 & 11.64 & 1.49 \\
\hline
\end{tabular}

$\Delta \mathrm{E}$ and $\mu(\mathrm{D})$ by ab initio.

TABLE 6: Net atomic charges for methyl-substituted oxazoles.

\begin{tabular}{lcccccccc}
\hline Compound & $\mathbf{1}$ & $\mathbf{2}$ & $\mathbf{3}$ & $\mathbf{4}$ & $\mathbf{5}$ & $\mathbf{6}$ & $\mathbf{7}$ & $\mathbf{8}$ \\
\hline Oxygen & -0.5273 & -0.5584 & -0.5338 & -0.5558 & -0.5626 & -0.5839 & -0.5619 & -0.5910 \\
C-2 & 0.3869 & 0.5754 & 0.3910 & 0.3902 & 0.5701 & 0.5642 & 0.3948 \\
Nitrogen & -0.5190 & -0.5495 & -0.5300 & -0.5105 & -0.5653 & -0.5455 & -0.5289 & -0.5685 \\
C-4 & -0.0217 & -0.0188 & 0.1385 & -0.0422 & 0.1426 & -0.0288 & 0.1185 & 0.1230 \\
C-5 & 0.1069 & 0.1024 & 0.0890 & 0.2914 & 0.0841 & 0.2899 & 0.2743 & 0.2709 \\
C-methyl 2 & - & -0.3949 & - & - & -0.3768 & -0.3769 & - & -0.3759 \\
C-methyl 4 & - & - & -0.3437 & - & -0.3436 & - & -0.3413 & -0.3410 \\
C-methyl 5 & - & - & - & -0.3733 & - & -0.3734 & -0.3676 & -0.3675 \\
\hline
\end{tabular}

Net charge calculated by ab initio.

TABLE 7: Net atomic charges for oxazole and cyanide-substituted oxazoles.

\begin{tabular}{lcccccrrr}
\hline Compound & $\mathbf{1}$ & $\mathbf{2}$ & $\mathbf{3}$ & $\mathbf{4}$ & $\mathbf{5}$ & $\mathbf{6}$ & $\mathbf{7}$ \\
\hline Oxygen & -0.5273 & -0.5306 & -0.5168 & -0.5261 & -0.5247 & -0.5330 & -0.5228 & -0.5338 \\
C-2 & 0.3869 & 0.6101 & -0.4057 & 0.4188 & 0.6279 & 0.6399 & 0.4211 & 0.6495 \\
Nitrogen & -0.5190 & -0.4837 & -0.4893 & -0.5110 & -0.4646 & -0.4895 & -0.4902 & -0.4711 \\
C-4 & -0.0217 & -0.0128 & 0.1180 & 0.0640 & 0.1242 & 0.0640 & 0.1924 & 0.1996 \\
C-5 & 0.1069 & 0.1244 & 0.1852 & 0.2827 & 0.2027 & 0.3118 & 0.3767 & 0.3989 \\
C-cyano-2 & - & 0.3132 & - & - & 0.3186 & 0.3146 & - & 0.3989 \\
C-cyano-4 & - & - & 0.3000 & - & 0.2972 & - & 0.3102 & 0.3100 \\
C-cyano-5 & - & - & - & 0.2934 & - & 0.2904 & 0.3076 & 0.3082 \\
\hline
\end{tabular}

Net charge calculated by ab initio.

on a grid method derived by Bodor et al. [19], using the atomic radii of Gavezzotti [20]. The polarizability was estimated from an additivity scheme given by Miller [21] with a precision on the calculation of $3 \%$, where different increments are associated with different atom types. The hydration energy is a key factor determining the stability of different molecular conformations [22].

The calculation is based on exposed surface area and employs the surface area as computed by the approximate method (above), weighted by atom type. 


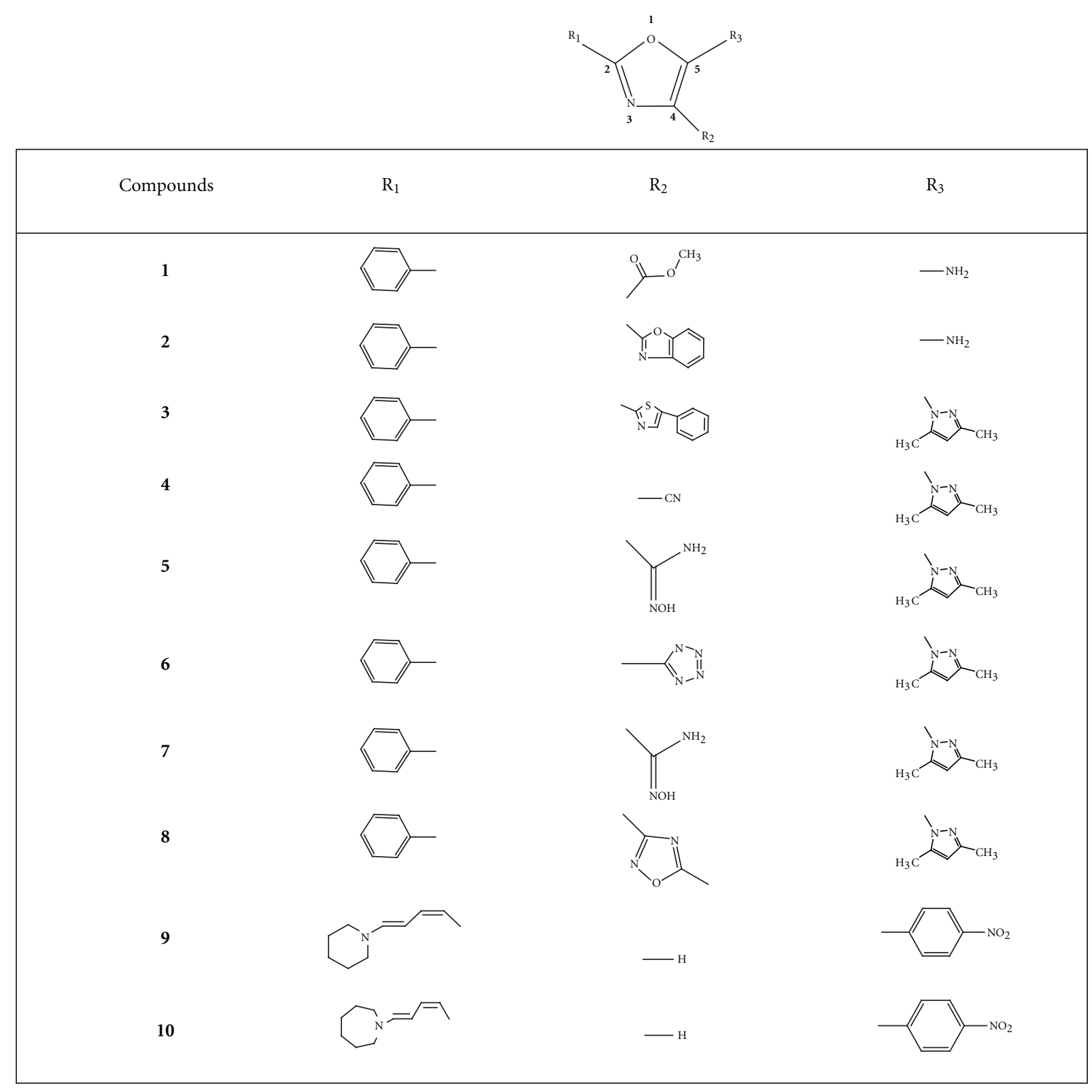

FIgURE 4: Structural comparison of the oxazole derivatives.

3.2.1. Structural Comparison of the Oxazole Derivatives. Based on our conclusions on the effect of substitution on the oxazole molecule. We chose a series of oxazole derivatives, some having a biological activity. This series of oxazole derivatives has been synthesized and characterized by Shablykin et al. [4, 23] and Rybakov et al. [24]. Initially, we performed a structural comparison of this series (Figure 4). These molecules have a weak conformational flexibility, with regard to the other macrocycles of macrolide type [2531 ]. In a window of $2 \mathrm{kcal} / \mathrm{mol}(\mathrm{MM})$, only one favored conformations are found, for each structure.

\subsubsection{Structure Physical-Chemistry Property Relationship.} The values of polarizability are generally proportional to the values of surfaces and of volumes; the decreasing order of polarizability for these studied oxazoles is $3,10,9,8,5,2,6,7$, 4 , and 1 (Table 8 ). The order of polarizability is the same one for volumes, but it is a bit little different for surfaces; that is due primarily to the folding up of surfaces of some structures compared to the majority of the extended structures. This is also explained by the relation between polarizability and volume, for the relatively nonpolar molecules.

The polarizability of the molecule depends only on its volume; the thermal agitation of the nonpolar molecules does not have any influence on the appearance of dipole moments in these molecules. On the other hand for the polar molecules, the polarizability of the molecule does not depend solely on volume but also depends on other factors such as the temperature, because of the presence of the permanent dipole [32]. 
TABLE 8: QSAR properties for oxazole derivatives.

\begin{tabular}{|c|c|c|c|c|c|c|}
\hline Oxazole derivative & $\begin{array}{c}\text { Molecular volume } \\
\left(\AA^{3}\right)\end{array}$ & $\begin{array}{c}\text { Molecular surface } \\
\left(\AA^{2}\right)\end{array}$ & $\begin{array}{l}\text { Molecular mass } \\
\quad \text { (uma) }\end{array}$ & $\begin{array}{c}\text { Partition } \\
\text { coefficient }(\log P)\end{array}$ & $\begin{array}{c}\text { Hydratation } \\
\text { energy }(\mathrm{Kcal} / \mathrm{mol})\end{array}$ & $\begin{array}{c}\text { Polarizability } \\
\left(\AA^{3}\right)\end{array}$ \\
\hline 1 & 635.96 & 408.51 & 218.21 & 0.04 & -09.57 & 22.29 \\
\hline 2 & 820.13 & 505.55 & 293.34 & 0.19 & -10.81 & 32.55 \\
\hline 3 & 1080.09 & 628.77 & 398.48 & 1.69 & -05.65 & 45.17 \\
\hline 4 & 779.16 & 477.05 & 264.29 & 1.41 & -06.60 & 28.89 \\
\hline 5 & 838.19 & 514.71 & 298.36 & 1.02 & -07.14 & 33.47 \\
\hline 6 & 842.66 & 503.32 & 307.31 & 2.51 & -17.71 & 32.44 \\
\hline 7 & 840.60 & 509.19 & 297.32 & 1.03 & -14.80 & 31.79 \\
\hline 8 & 906.05 & 547.44 & 321.34 & 1.85 & -05.80 & 34.27 \\
\hline 9 & 880.91 & 506.41 & 325.37 & -3.41 & -07.23 & 35.09 \\
\hline 10 & 960.21 & 553.23 & 339.39 & -3.01 & -07.91 & 36.93 \\
\hline
\end{tabular}

The surface and the volume of distribution of these molecules are definitely higher than that of more polar molecules like the lipopeptides or beta-lactams. For example, Deleu et al. used TAMMO software [33] on the surfactins $\mathrm{C} 13, \mathrm{C} 14$, and $\mathrm{C} 15$ having cores similar to the macrolides. They found that their surfaces vary from 129 to $157 \AA^{2}$ [34]; contrarily for these oxazoles, surfaces vary from 409 to $629 \AA^{2}$. These oxazoles have a great variation of distribution volume, in particular compound $\mathbf{3}$ and compound $\mathbf{1 0}$ which have respective volumes: 1080 and $960 \AA^{3}$ (Table 8).

The hydration energy in the absolute value, most important is that of the compound $6(17.7 \mathrm{kcal} / \mathrm{mol})$ and the weakest is that of compound $3(5.6 \mathrm{kcal} / \mathrm{mol})$ (Table 8$)$. Indeed, in the biological environments the polar molecules are surrounded by water molecules. They are established hydrogen bonds between a water molecule and these molecules. The donor sites of proton interact with the oxygen atom of water, and the acceptor sites of proton interact with the hydrogen atom.

The first corresponds to the complex with the strongest hydrogen bond. These hydrated molecules are dehydrated at least partially before and at the time of their interaction. These interactions of weak energy, which we observe in particular between messengers and receivers, are generally reversible [35]. Compound 6 has a site donor of proton ( $1 \mathrm{NH}$ on the alkyl group/ $\mathrm{R}_{3}$ ) and seven acceptor sites of proton $(5 \mathrm{~N}$ on the alkyl groups and $1 \mathrm{~N}, 1 \mathrm{O}$ on the principal cycle). On the other hand, the compound 3 does not possess any donor site but possess five acceptor sites of proton $(3 \mathrm{~N}$, on the alkyl groups, $1 \mathrm{~N}$ and $1 \mathrm{O}$ on the principal cycle,) With the first having higher value, it has two more acceptor sites of protons and one donor site. This property supports the first compound, not only by fixing the receiver, but also activates it. It is thus about an agonist. The compound 9 presents the low coefficient of division $(-3.41)$ and comes after the compound $\mathbf{1 0}(-3.01)$. These molecules are the most absorbent products. When the coefficient of division is rather low, it has as a consequence a better gastric tolerance. The compounds 6 and 8 which have, respectively, higher values 2.51 and 1.85 have capacities to be dependent on plasmatic proteins.

\section{Conclusion}

The present work on the oxazoles reveals that the substitution of methyl and cyanide group does not affect the heat of formation but the electronic parameters due to charge disturbance in the ring. In the substituted methyl group, 2, 4, 5-trimethyl oxazole is predicted to be the most reactive with least HOMO-LUMO energy gap of all oxazole systems.

The DFT and ab initio method can be used quite satisfactorily in predicting the chemical reactivity of the molecules and the effect of substitution of either donor electron or acceptor electron.

The compound 9 in the series of oxazole derivatives presents the lower coefficient of division $(\log P)$.

This molecule is the most absorbent product. Compound 6 has important hydration energy. It has as a consequence a better distribution in fabrics.

\section{References}

[1] D. A. Bakhotmah, R. M. Abdul-Rahman, M. S. Makki, M. A. El-Zahabi, and M. Suliman, "Synthesis, physiochemical properties, photochemical probe, and antimicrobial effects of novel norfloxacin analogues," ISRN Organic Chemistry, vol. 2011, Article ID 184754, 11 pages, 2011.

[2] E. G. Robertson, "Vibrational assignment of isoxazole aided by rovibrational data and density functional theory," Journal of Molecular Spectroscopy, vol. 231, no. 1, pp. 50-56, 2005.

[3] H. Agirbas, S. Guner, F. Budak et al., "Synthesis and structure-antibacterial activity relationship investigation of isomeric 2,3,5-substituted perhydropyrrolo[3,4-d] isoxazole4,6-diones," Bioorganic and Medicinal Chemistry, vol. 15, no. 6, pp. 2322-2333, 2007.

[4] O. V. Shablykin, V. S. Brovarets, and B. S. Drach, "Synthesis of new derivatives of 5-amino-1,3-oxazole basing on 3benzoylamino-3,3-dichloroacrylonitrile," Russian Journal of General Chemistry, vol. 77, no. 7, pp. 1308-1309, 2007.

[5] M. H. Palmer, R. Wugt Larsen, and F. Hegelund, "Comparison of theoretical and experimental studies of infrared and microwave spectral data for 5- and 6-membered ring heterocycles: the rotation constants, centrifugal distortion and vibration rotation constants," Journal of Molecular Spectroscopy, vol. 252, no. 1, pp. 60-71, 2008. 
[6] S. Belaidi, M. Mellaoui, M. Lemchounchi, and O. Youcef, "A-initio/HF investigation on the effect of methyl group perturbations in isoxazoles and isothiazoles," in Proceedings of the 8th Congress of the Algerian Society of Chemistry, Bejaia, Algeria, May 2009.

[7] O. Abdelmalek, S. Belaidi, M. Mellaoui, and R. Mazri, "Geometric and electronic structure of isoxazole and isothiazole derivatives by PM3 and density functional theory," Asian Journal of Chemistry, vol. 23, no. 3, pp. 1183-1185, 2011.

[8] W. J. Hehre, Practical Strategies for Electronic Structure Calculations, Wavefunctions, Irvine, Calif, USA, 1995.

[9] E. R. Davidson, "Quantum theory of matter: introduction," Chemical Reviews, vol. 91, no. 5, p. 649, 1991.

[10] Y. C. Martin, Quantitative Drug Design, Marcel Dekker, New York, NY, USA, 1978.

[11] HyperChem (Molecular Modeling System) Hypercube, Inc, 1115 NW, 4th Street, Gainesville, FL 32601; USA, 2007, http://www.hyperchem.com/.

[12] M. W. Wong, K. B. Wiberg, and M. J. Frisch, "Solvent effects. 3. Tautomeric equilibria of formamide and 2-pyridone in the gas phase and solution. An ab initio SCRF study," Journal of the American Chemical Society, vol. 114, no. 5, pp. 1645-1652, 1992.

[13] V. Barone and C. Adamo, "Density functional study of intrinsic and environmental effects in the tautomeric equilibrium of 2-pyridone," Journal of Physical Chemistry, vol. 99, no. 41, pp. 15062-15068, 1995.

[14] G. L. Miessler and D. A. Tarr, Inorganic Chemistry, PrenticeHall, Upper Saddle River, NJ, USA, 2nd edition, 1999.

[15] A. Weissberger, The Chemistry of Heterocyclic Compounds, John Wiley \& Sons, New York, NY, USA, 1993.

[16] L.B. Kier, Molecular Orbital Theory in Drug Research, Academic Press, New York, NY, USA, 1971.

[17] V. N. Viswanadhan, A. K. Ghose, G. R. Revankar, and R. K. Robins, "Atomic physicochemical parameters for three dimensional structure directed quantitative structure-activity relationships. 4. Additional parameters for hydrophobic and dispersive interactions and their application for an automated superposition of certain naturally occurring nucleoside antibiotics," Journal of Chemical Information and Computer Sciences, vol. 29, pp. 163-172, 1989.

[18] A. K. Ghose and G. M. Crippen, "Atomic physicochemical parameters for three-dimensional-structure-directed quantitative structure-activity relationships. 2. Modeling dispersive and hydrophobic interactions," Journal of Chemical Information and Computer Science, vol. 27, pp. 21-35, 1987.

[19] N. Bodor, Z. Gabanyi, and C. K. Wong, "A new method for the estimation of partition coefficient," Journal of the American Chemical Society, vol. 111, no. 11, pp. 3783-3786, 1989.

[20] A. Gavezzotti, “The calculation of molecular volumes and the use of volume analysis in the investigation of structured media and of solid-state organic reactivity," Journal of the American Chemical Society, vol. 105, no. 16, pp. 5220-5225, 1983.

[21] K. J. Miller, "Additivity methods in molecular polarizability," Journal of the American Chemical Society, vol. 112, no. 23, pp. 8533-8542, 1990.

[22] T. Ooi, M. Oobatake, G. Némethy, and H. A. Scheraga, "Accessible surface areas as a measure of the thermodynamic parameters of hydration of peptides," Proceedings of the National Academy of Sciences of the United States of America, vol. 84, no. 10, pp. 3086-3090, 1987.
[23] O. V. Shablykin, V. S. Brovarets, and B. S. Drach, "New transformations of 5-Hydrazino-2-phenyl-1,3-oxazole-4-carbonitrile," Russian Journal of General Chemistry, vol. 77, no. 5, pp. 936-939, 2007.

[24] V. B. Rybakov, E. V. Babaev, A. A. Tsisevich, A. V. Arakcheeva, and A. Schoenleber, "X-ray mapping in heterocyclic design: IX. X-ray structure investigation of conjugated aminodienes," Crystallography Reports, vol. 47, no. 6, pp. 973-978, 2002.

[25] S. Belaidi, A. Dibi, and M. Omari, "A conformational exploration of dissymmetric macrolides antibiotics," Turkish Journal of Chemistry, vol. 26, no. 4, pp. 491-500, 2002.

[26] S. Belaidi, M. Laabassi, R. Gree, and A. Botrel, "Conformational analysis of symmetrical macrolides, from 12 to 28 membered, based on molecular mechanics," Scientific Study \& Research, vol. 4, pp. 27-38, 2003.

[27] S. Belaidi, T. Lanez, M. Omari, and A. Botrel, "Quantitative conformational analysis of dissymmetric macrolides by molecular modelling," Asian Journal of Chemistry, vol. 17, no. 2, pp. 859-870, 2005.

[28] S. Belaidi, M. Omari, T. Lanez, and A. Dibi, "Contribution to the study of structure-activity relationship in new antibiotic macrolides," Journal of the Algerian Society of Chemistry, vol. 14, pp. 27-39, 2004.

[29] S. Belaidi, M. Laabassi, R. Gree, and A. Botrel, "New approach to the stereoselectivity of macrolide antibiotics with 20 atoms chains through molecular modelization," Revue Roumaine de Chimie, vol. 50, no. 9-10, pp. 759-765, 2005.

[30] S. Belaidi, M. Omari, and T. Lanez, "Stereochemical analysis in 22-membered macrolides based on molecular modeling," Annals of the Faculty of Sciences and Engineering Sciences, vol. 1, pp. 1-4, 2006.

[31] S. Belaidi and D. Harkati, "Conformational analysis in 18membered macrolactones based on molecular modeling," ISRN Organic Chemistry, vol. 2011, Article ID 594242, 5 pages, 2011.

[32] B. Yavorski and A. Detlaf, Checklist of Physics, Mir, Moscow, Russia, 1980.

[33] TAMMO, Theoretical Analysis of Molecular Membrane Organization, CRC Press, Boca Raton, Fla, USA, 1995.

[34] M. Deleu, Synthesis of surfactin derivatives and study their properties, Thesis Ph.D, FUSAGX, Belgique, 2000.

[35] L. B. Kier, Molecular Orbital Theory in Drug Research, Academic Press, New York, NY, USA, 1981. 


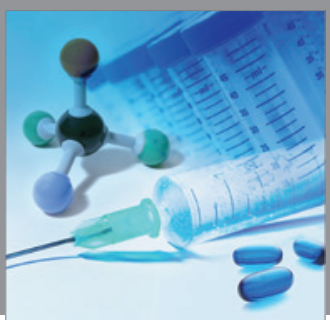

International Journal of

Medicinal Chemistry

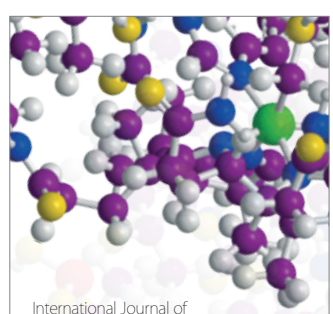

Carbohydrate Chemistry

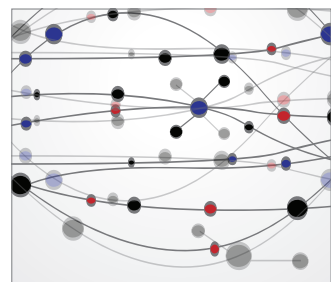

The Scientific World Journal
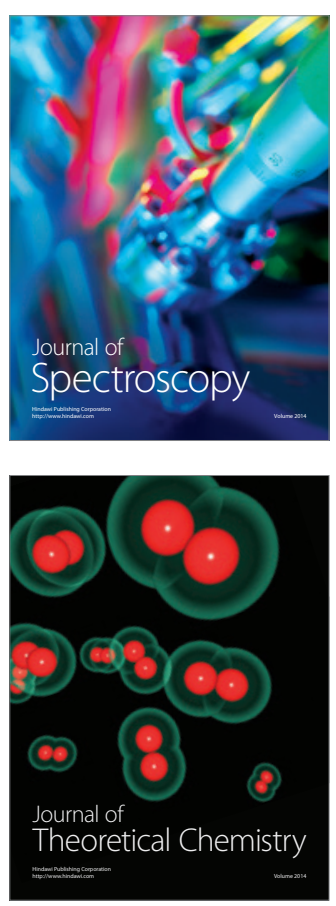
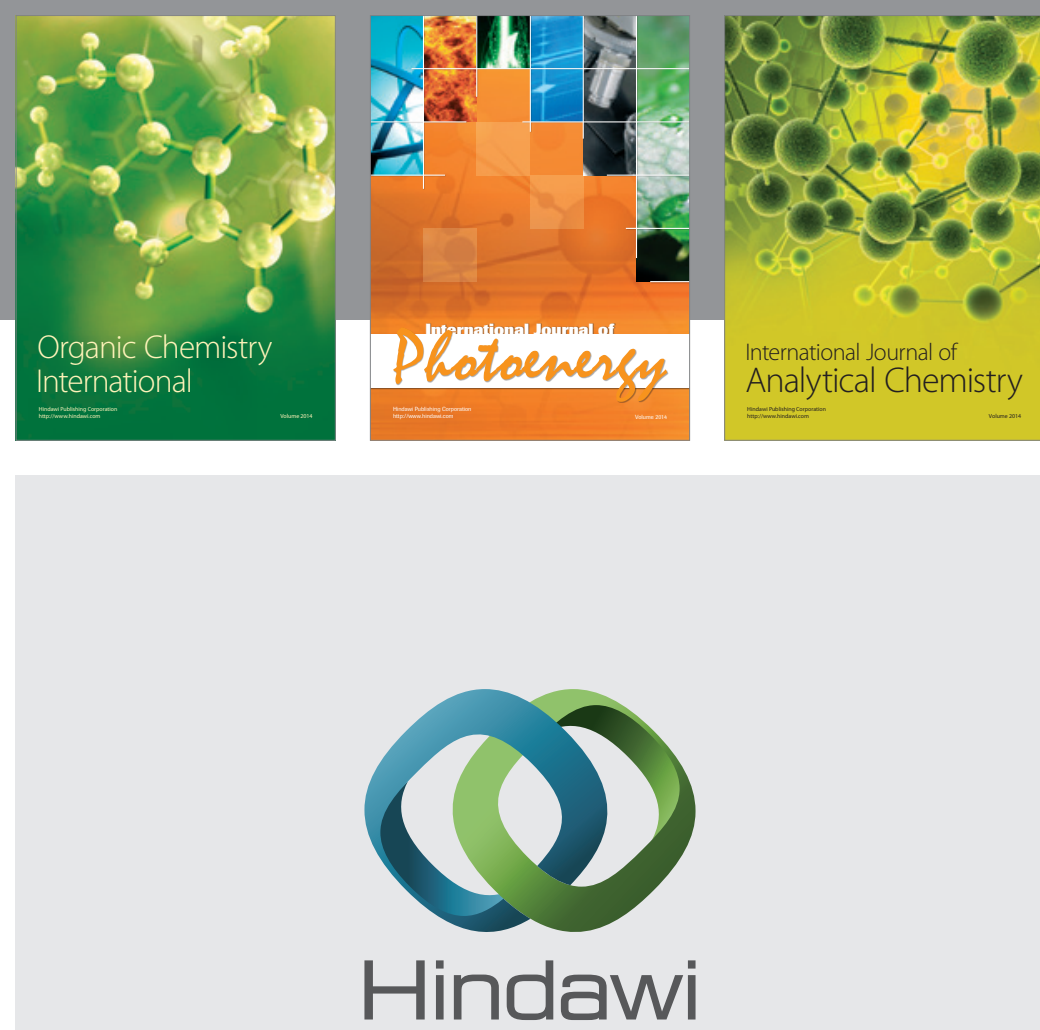

Submit your manuscripts at

http://www.hindawi.com
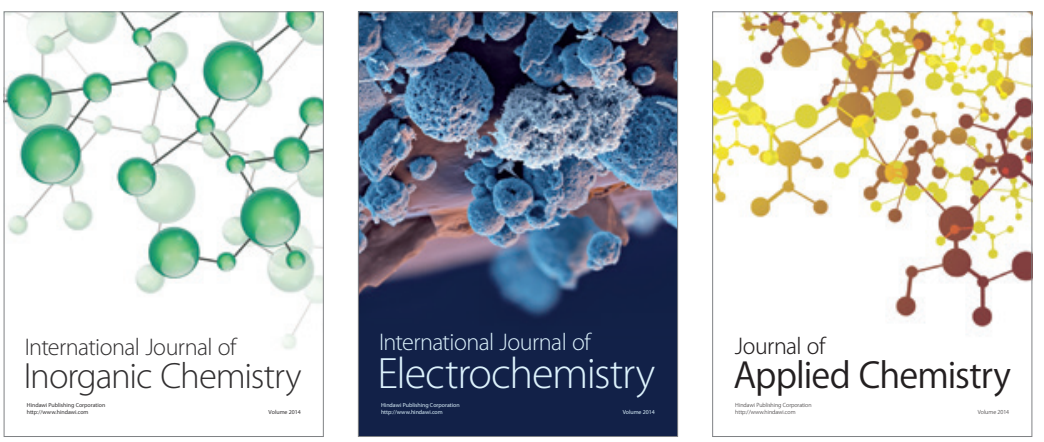

Journal of

Applied Chemistry
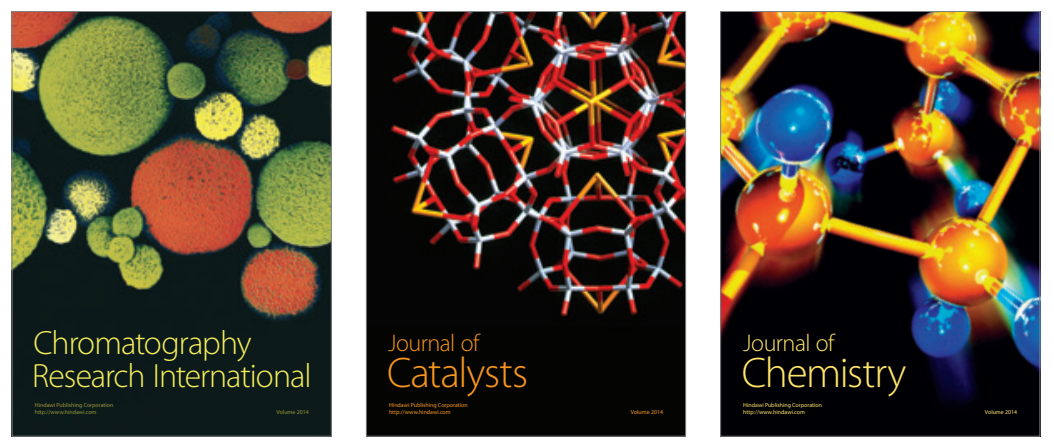
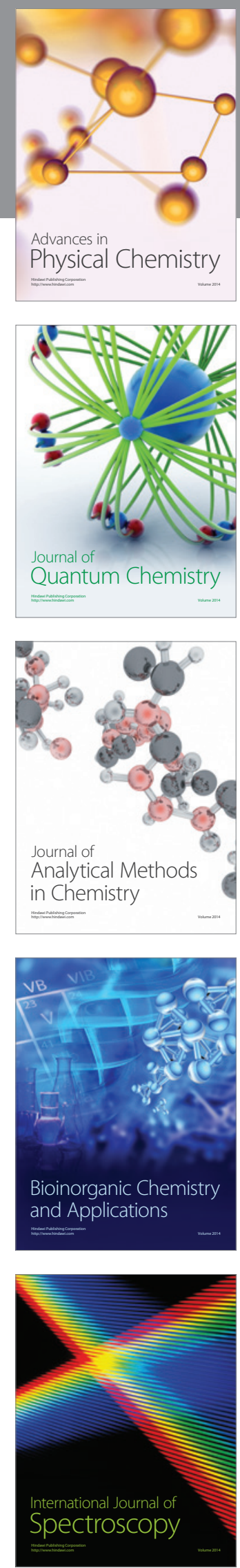